\title{
Systemic Contact Dermatitis: Current Challenges and Emerging Treatments
}

\author{
Heather P. Lampel, MD MPH ${ }^{1, *}$ \\ Dianne L. Silvestri, $M D^{2}$
}

\author{
Address \\ *,1Department of Dermatology, Duke University Medical Center, 5324 McFarland \\ Drive Suite 210, Durham, NC 27707, USA \\ e-mail: heather.lampel@duke.edu \\ ${ }^{2}$ Division of Dermatology, University of Massachusetts Medical Center, 281 Lincoln \\ Street, Worcester, MA 01605, USA \\ e-mail: dianne.silvestri@umassmemorial.org \\ Published online: 2 August 2014 \\ (C) Springer International Publishing AG 2014
}

Keywords Dermatitis - Systemic - Nickel - Cobalt - Balsam of Peru - Myroxylon pereirae - Chromate · Formaldehyde Propylene glycol · Compositae - Parabens - Sorbic acid • Allergic contact dermatitis - Disulfuram - Hyposensitization • Allergy · Diet · Food · Systemic contact dermatitis - Allergen - Avoidance diet - Elimination diet · Aspartame

\section{Opinion statement}

Systemic contact dermatitis (SCD) is poorly understood, and its very existence has even been questioned. Allergic contact dermatitis (ACD) is an immune-mediated, delayed-type hypersensitivity (type-IV) reaction, usually manifesting itself as a visible and symptomatic inflammation of the skin. The majority of patients diagnosed with ACD improve clinically with allergen avoidance. The mainstay of avoidance for most allergens is the prevention of skin contact through discontinuation of products that contain the allergen(s), the selection of alternatives from "safe lists," and counseling patients on environmental sources of allergens. While ACD affects a large percentage of the population, relatively few patients have been documented as having had a significant contribution to their allergic state by allergen exposure through sources other than by cutaneous contact. SCD is defined as provocation or exacerbation of dermatitis by non-cutaneous exposure to an allergen in a patient who is already cutaneously sensitized. Exposure routes in SCD are varied, with the most common and frequently documented being oral exposure. Diet may be an important source of exposure to contact allergens in some patients with $A C D$, and low-allergen diets have been developed for some common allergens, such as nickel, cobalt, and Balsam of Peru (Myroxylon pereirae). When contact avoidance and dietary restriction of allergen fail, escalation from topical treatments to systemic immune-suppressants may be necessary. Emerging therapies such as nickel oral hypo-sensitization may be beneficial in the future. 


\section{Introduction}

Allergic contact dermatitis (ACD) has an approximate prevalence of $20 \%$ [1]. We do not know the exact prevalence of systemic contact dermatitis (SCD), but it is thought to be much less common. While most sensitized patients improve with cutaneous allergen avoidance, others require avoidance of systemic sources, such as a specialized diet to also limit oral exposure to allergens. Low-allergen diets have been developed for specific common allergens, and these diets are recommended in practice when necessary. Early reports of somewhat successful hypo-sensitization are being revisited, with the potential for future therapy.

\section{Epidemiology}

The incidence and prevalence of ACD in the general population has been difficult to study. A thoughtful review by Thyssen et al., in 2007 estimated the median prevalence of contact allergy in the general population as $21.2 \%$, with a weighted average prevalence of $19.5 \%$. The most common allergens noted were nickel, thimerosal, and fragrance mix. The median nickel allergy prevalence was noted to be $8.6 \%$ [1].

Unfortunately, no epidemiological data exist for SCD in the general population. Challenges in the collection of this information include the large number of allergens that can cause SCD, the clinical basis for the diagnosis of SCD, and the diversity of clinical presentations of SCD. However, a meta-analysis of 17 studies of oral nickel exposure estimated that $1 \%$ of nickelsensitive patients may react systemically to everyday nickel exposure (0.22- $0.35 \mathrm{mg}$ nickel), and $10 \%$ may react to a diet composed of foods rich in nickel (0.55$1.33 \mathrm{mcg}$ nickel) [2]. Furthermore, European literature has noted the emergence of a "systemic nickel allergy syndrome" or SNAS, defined as nickel-induced SCD with extracutaneous symptoms. Of 1,696 patients referred to allergy units in Italy, 98 (5.78 \%) were diagnosed with SNAS [3].

\section{Pathogenesis}

SCD is defined as non-cutaneous exposure to an allergen causing dermatitis in a person who is already cutaneously sensitized [4]. The pathogenesis of ACD has been well-described, and involves an immune-mediated sensitization and elicitation phase. After sensitization, exposure to the allergen administered through a route other than skin contact is thought to elicit an immune response that produces cutaneous manifestations. Common routes of exposure include oral, intra-articular, intramuscular, intravenous, inhalation, and subcutaneous, among others [5]. While ACD has been described as a type IV delayed-type hypersensitivity, SCD may also involve a type III immune response, as antigen-antibody complexes have been found in the skin [6], and in the blood [7], in such reactions.

\section{Presentation}

The clinical presentation of SCD can vary widely. While SCD may be clinically indistinguishable from ACD, unique presentations are also recognized. Baboon syndrome has been used to describe a SCD manifesting as erythema of the buttocks and flexural skin [8]. If this presentation is drug-related, it has been denoted symmetric drug-related intertriginous and flexural exanthema (SDRIFE) [9]. Vesicular hand (and possibly foot) dermatitis has also been described and is most commonly associated with metals, specifically oral administration of nickel, cobalt and chromium [10-15], as can the ingestion of spices [16]. Similarly, perianal dermatitis [17, 18] and "recall" dermatitis, reactivation of a patch test site $[19,20]$ or of prior dermatitis $[21,22]$, have been ascribed to SCD.

\section{Diagnosis}

The epicutaneous patch test remains the gold standard for diagnosing ACD. When patients do not clinically improve with prescribed topical avoidance of relevant allergens, SCD should be added to the differential diagnosis. Certain allergens are more likely than others to cause SCD, and consideration of the potential relevance of non-cutaneous sources of exposure should be undertaken. The diagnosis of SCD is supported when a patient improves after avoidance of exposure by oral or another route to the proven allergen. Typically, rechallenge of a patient with this allergen via the non-cutaneous route helps confirm the diagnosis.

\section{Prognosis}

With regard to oral exposure, ability to adhere to a diet may impact the prognosis of a patient with SCD. Some diets are more difficult to follow than others, and individual patient preference for foods may also affect success or failure with prescribed low-allergen diets. 
Additionally, individuals may have different thresholds of response, and some more sensitive patients may have to adhere more stringently than others to control symptoms.

\title{
Treatment
}

\section{Diet and lifestyle}

- SCD with oral allergen exposure is managed with dietary avoidance (Table 1). Poor compliance or inability to maintain restriction in the setting of persistent symptoms may merit consideration of phototherapy or immunosuppressant therapy. Oral hypo-sensitization has been reported as a possible future treatment for the systemic nickel allergy syndrome (SNAS) subgroup of patients.

- An algorithmic approach to management of dermatitis in a patient with clinically relevant positive epicutaneous patch test can be found in Fig. 1.

\section{Nickel}

- Nickel-sensitive patients may improve with a low-nickel diet [2, 18, 23].

- A points-based nickel diet system has been developed to assist with adherence to nickel dietary restriction. This system allocates gradations of points from 0 to 10 based on the amount of nickel found in the food. Adults are allocated 15 points daily to "spend" on foods listed, children under 12 are allocated 10 points daily, and very sensitive individuals should be restricted to 5 points daily. It is recommended that foods containing beans, granola, chocolate, peanuts, soy, and oatmeal be avoided altogether, given their very high nickel content $[24 \bullet \bullet]$.

- Water can also be a source of nickel. Drinking bottled or distilled water $[24 \bullet \bullet]$ may be helpful. Alternatively, if the water has been sitting in the

\section{Table 1. Diet-related allergens associated with systemic contact dermatitis}

\author{
Balsam of Peru (Myroxylon pereirae) \\ Chromate \\ Cobalt \\ Compositae (Asteraceae) \\ Formaldehyde \\ Nickel \\ Parabens \\ Propylene Glycol \\ Sorbic acid
}




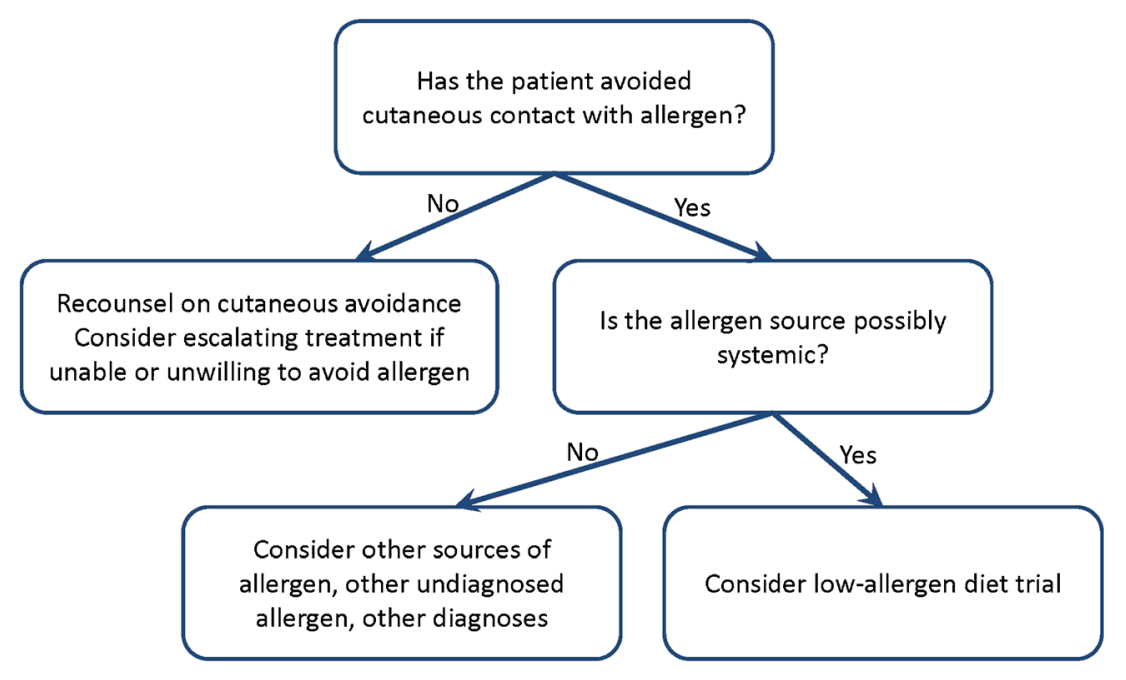

Fig. 1. Management of dermatitis in the patient with clinically relevant positive epicutaneous patch test

pipes for some time, a few liters should be expelled before consumption or use, as nickel can leach into the water from the pipes [25].

- Cooking in stainless steel pots and pans should be avoided, as nickel can leach into foods. Acidic foods such as citrus, tomato-based meals, and vinegar may also contribute to this phenomenon [26]. Similarly, stainless steel utensils should not be used while cooking acidic foods [27].

- Both processed foods and canned foods may have higher than expected nickel content due to packaging and processing equipment [28].

- The soil in which a food is grown may affect the food's nickel content [29].

- Absorption of nickel may vary depending on patient health and overall diet. Vitamin C [30] and iron [31] decrease the dietary absorption of nickel [28]. Taking a chewable $500 \mathrm{mg}$ or $1000 \mathrm{mg}$ vitamin $\mathrm{C}$ tablet

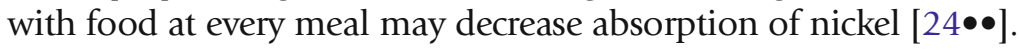
Patients with iron-deficiency anemia may absorb more nickel from the diet than expected $[27,32]$. Avoidance of any nickel-containing mul-

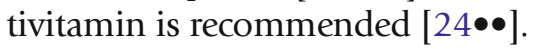

- If constipation occurs following a low-nickel diet, taking a stool soft-

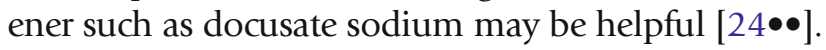

\section{Cobalt}

- Cobalt is a constituent of vitamin B12. Naturally occurring B12, comprised of adenosylcobalamin and methylcobalamin, does not cause hypersensitivity reactions [13]. However, there are reports of reactions to synthetically derived B12, both cyanocobalamin and hydroxycobalamin [33, 34].

- It is thought that it is the cobalt itself, rather than the vitamin B12 in foods, that contributes to SCD [13]. 
- A low-cobalt points-driven diet has been developed to facilitate dietary cobalt restriction. Patients are limited to 12 points daily, and portioned foods are assigned a point value of 1-7 depending on cobalt content [13].

- Brazil nuts, cow liver and herbal/homeopathic remedies are not permitted on this diet due to elevated cobalt levels [13].

- Contributions to the overall cobalt exposure burden include smoking and industrial sources [35].

\section{Chromate}

- Avoiding foods high in chromate may be necessary in chromiumsensitive patients [36]. These foods include red wine [37], whole grains and bran, potatoes, meats, fruits such as apples and bananas, orange and grape juice, beans and nuts, vegetables such as broccoli and green beans, brewer's yeast, black pepper, coffee and tea [38-40].

- Canned food, hard water, and chromium-containing drinks and supplements should be avoided [36].

- Cooking in aluminum cookware decreases the chromium content of food while using stainless steel cookware increases the chromium content [36].

- Foods containing simple sugars, such as fructose and sucrose, may help eliminate chromium [36].

- BOP (Myroxylon pereirae) is a commonly used fragrant sap-derived substance from a tree in Central America. It consists of a conglomerate of numerous potential allergens, including vanillin, cinnamates, ben-

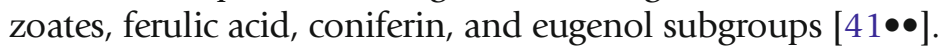

- Numerous foods may contain spices and flavorings problematic for individuals sensitized to BOP or any of its many components. On a low-BOP diet, it is important to avoid citrus (including essence, oil, and peel); sweet baked goods; spices such as cinnamon, cloves, vanilla, curry, allspice, anise, and ginger; pickled foods; tomato-based sauces; spicy condiments; select alcohols such as certain wines, gin and vermouth; chocolate; ice cream; and flavored soft drinks, including colas. Any spiced tobacco or medicinal product should also be avoided [42].

- It is likely that not all patients with BOP-related systemic contact der-

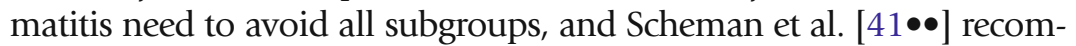
mend further classification and testing for the subgroups eugenol, vanillin, cinnamates, benzoates, ferulic acid, and coniferin. Knowing the specific BOP allergen subgroup(s) can help identify more specific foods to avoid, rather than eliminating the broad list above $[41 \bullet \bullet]$. 
- It is listed on the ingredient label, and may be found in numerous

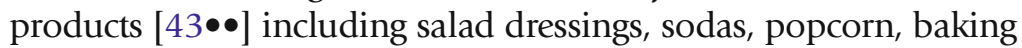
mixes [44], prepackaged breakfast items, fast foods, prepared meals,

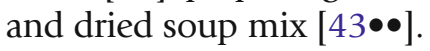

- Avoidance of consumable members of the Compositae family may be necessary, including chamomile tea, lettuce, echineacea, chicory, and endive [45].

\section{Formaldehyde}

- Formic acid is a metabolite of aspartame, and aspartame may need to be avoided in formaldehyde-sensitive patients [46]. Some foods that contain aspartame include chewable vitamins, weight-loss drinks, protein powders and bars, diet drinks including sodas, and low-calorie or sugar-free foods $[43 \bullet \bullet]$.

- Parabens are used as preservatives, and are not highly allergenic [47]. Foods with higher content of parabens include pickles, prepared baked goods, syrup, and jelly/jam/marmalade [48].

- Sorbates are preservatives found in prepackaged foods and should be listed on the label if present. Some prepackaged dairy and meat products contain sorbates, as can selected cereals, juice, prepared drinks and

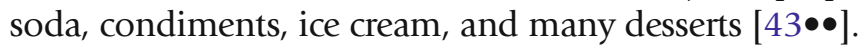

\section{Pharmacologic treatment}

- When dietary avoidance is not practical or possible, systemic immune-suppressants such as azathioprine, cyclosporine, methotrexate, and mycophenolate mofetil may be considered after a trial of topical steroids or calcineurin inhibitors if appropriate [49•]. Disulfiram has been used rarely in nickel systemic contact allergy with some success, but it remains a nonconventional therapy [49•]. Primarily used in treatment for alcohol addiction, disulfiram is metabolized by the liver into sodium diethyldithiocarbamate, which in turn chelates nickel and cobalt. Increased excretion of nickel ensues via bile, urine, and sweat 
[50, 51]. Multiple studies have confirmed improvement in recalcitrant nickel-sensitive patients with use of disulfiram [49•].

\section{Interventional procedures}

- The use of ultraviolet light treatment in hand eczema can be effective [52]. It is also used for localized and diffuse dermatitis. Narrow-band ultraviolet B (NBUVB) light, ultraviolet A (UVA) light, and topical or systemic psoralen with ultraviolet A (PUVA) light are potential options for phototherapy. Contraindications to phototherapy include exogenous or endogenous sun-sensitivity and a personal history of melanoma, while history of nonmelanoma skin cancer is a relative contraindication.

\section{Emerging therapies}

- Hypo-sensitization is an emerging treatment in the field of systemic allergic contact dermatitis. Oral hypo-sensitization has been reported to have had some success in the treatment of cobalt-sensitive [53], and nickel-sensitive patients $[54 \bullet, 55]$.

- A recently published randomized, double-blind, placebocontrolled trial addressed patients with a diagnosis of SNAS. These patients had not only skin symptoms, but also extracutaneous complaints, commonly gastrointestinal, which were associated with nickel consumption. The group treated with the highest dose of nickel weekly was able to tolerate reintroduction of nickel-rich foods better than the placebo group, and required less use of rescue medications. Higher nickel doses after treatment were required to elicit a symptomatic flare as compared to pre-treatment. Gastrointestinal symptoms were statistically significantly improved in this same group as compared to placebo; skin symptoms were improved, though not statistically significantly [54•].

- The mechanism of hypo-sensitization is still being investigated. Following nickel oral hypo-sensitization therapy, there are cytokine changes from a primarily Th2 profile to an increase in IL-10 [56], which is a regulatory cytokine [57]. Cavani et al. [58] postulate that the proliferation and differentiation of $\mathrm{T}$ regulatory cells may lead to increased tolerance of nickel after hyposensitization therapy. 


\section{Pediatric considerations}

- Compared to adults, children may have similar oral exposure to contact allergens, with the exception of fewer medication exposures [59•]. Special considerations in children include repeated or high consumption of particular foods or condiments, such as ketchup [60]. Adherence to a low-allergen diet may require both patient and parent involvement.

\section{Compliance with Ethics Guidelines}

Conflict of Interest

Heather P. Lampel declares that she has no conflict of interest.

Dianne L. Silvestri declares that she has no conflict of interest.

Human and Animal Rights and Informed Consent

This article does not contain any studies with human or animal subjects performed by any of the authors.

\section{References and Recommended Reading}

Papers of particular interest, published recently, have been

highlighted as:

- Of importance

$\bullet$ Of major importance

1. Thyssen JP, Linneberg A, Menné T, et al. The epidemiology of contact allergy in the general population prevalence and main findings. Contact Dermatitis. 2007;57(5):287-99.

2. Jensen CS, Menné T, Johansen JD. Systemic contact dermatitis after oral exposure to nickel: a review with a modified meta-analysis . Contact Dermatitis. 2006;54(2):79-86.

3. Ricciardi L, Arena A, Arena E, et al. Systemic nickel allergy syndrome: epidemiological data from four Italian allergy units. Int J Immunopathol Pharmacol. 2014;27(1):131-6.

4. Wolf R, Orion E, Ruocco E, et al. Contact dermatitis: facts and controversies. Clin Dermatol. 2013;31:467-78.

5. Veien NK. Ingested food in systemic allergic contact dermatitis. Clin Dermatol. 1997;15:547-55.

6. Veien NK, Menné T. Systemic contact dermatitis. In: Frosh PJ, Menne T, Lepoittevin JP, editors. Contact dermatitis. Berlin-Heidelberg : Springer; 2006. p. 295-307.

7. Veien NK, Christiansen AH, Svejgaard E, et al. Antibodies against nickel-albumin in rabbits and man. Contact Dermatitis. 1979;5(6):378-82.

8. Anderson KE, Hjorth N, Menné T. The baboon syndrome: systemically-induced allergic contact dermatitis. Contact Dermatitis. 1984;10(2):97-100.
9. Hausermann TH, Bircher AJ. Baboon syndrome resulting from systemic drugs: is there strife between SDRIFE and allergic contact dermatitis syndrome? Contact Dermatitis. 2004;51(5-6):297-310.

10. Jensen CS, Menné T, Lisby S, et al. Experimental systemic contact dermatitis from nickel: a dose-response study. Contact Dermatitis. 2003;49(3):124-32.

11. Veien NK, Hattel T, Justesen $\mathrm{O}$, et al. Oral challenge with nickel and cobalt in patients with positive patch tests to nickel and/or cobalt. Acta Derm Venereol. 1987;67(4):321-5.

12. Veien NK, Hattel T, Laurberg G. Placebo-controlled oral challenge with cobalt in patients with positive patch tests to cobalt. Contact Dermatitis. 1995;33(1):54-5.

13. Stuckert J, Nedorost S. Low-cobalt diet for dyshidrotic eczema patients. Contact Dermatitis. 2008;59(6):361-5.

14. Veien NK, Kaaber K. Nickel, cobalt and chromium sensitivity in patients with pompholyx (dyshidrotic eczema). Contact Dermatitis. 1979;5(6):371-4.

15. Nielsen GD, Jepsen LV, Jørgensen PJ, et al. Nickelsensitive patients with vesicular hand eczema: oral challenge with a diet naturally high in nickel. Br J Dermatol. 1990;122(3):299-308. 
16. Niinimäki A. Delayed-type allergy to spices. Contact Dermatitis. 1984;11(1):34-40.

17. Vermaat H, Smienk F, Rustemeyer T, et al. Anogenital allergic contact dermatitis: the role of spices and flavour allergy. Contact Dermatitis. 2008;59(4):233-7.

18. Silvestri DL, Barmettler S. Pruritus ani as a manifestation of systemic contact dermatitis: resolution with dietary nickel restriction. Dermatitis. 2011;22(1):50-5.

19. Möller H, Ohlsson $\mathrm{K}$, Linder $\mathrm{C}$, et al. The flare-up reactions after systemic provocation in contact allergy to nickel and gold. Contact Dermatitis.

1999;40(4):200-4.

20. Isaksson M, Bruze M. Allergic contact dermatitis in response to budesonide reactivated by inhalation of the allergen. J Am Acad Dermatol. 2002;46(6):880-5.

21. Giordano-Labadie F, Pech-Ormieres C, Bazex J. Systemic contact dermatitis from sorbic acid. Contact Dermatitis. 1996;34(1):61-2.

22. Fisher AA. Systemic contact dermatitis due to intravenous Valium in a person sensitive to propylene glycol. Cutis. 1995;55(6):327-8.

23. Zirwas MJ, Molenda MA. Dietary nickel as a cause of systemic contact dermatitis. J Clin Aesthet Dermatol. 2009;2(6):39-43.

24.• Mislankar M, Zirwas MJ. Low-nickel diet scoring system for systemic nickel allergy. Dermatitis.

2013;24(4):190-8. This original article serves as a guide for patients following a low-nickel diet.

This original article serves as a guide for patients following a low-nickel diet. This points-based low-nickel diet indexes numerous foods in an easy-to-read manner

25. Andersen KE, Nielsen GD, Flyvholm MA, et al. Nickel in tap water. Contact Dermatitis. 1983;9(2):140-3.

26. Kuligowski J, Haperin KM. Stainless steel cookware as a significant source of nickel, chromium, and iron. Arch Environ Contam Toxicol. 1992;23(2):211-5.

27. Sharma AD. Low nickel diet in dermatology. Indian J Dermatol. 2013;58(3):240.

28. Joneja JM. Section III: specific food restrictions: nickel allergy. In: Joneja JM (ed) Managing food allergy and intolerance: a practical guide. JA Hall Publications, Ltd, 2nd ed; 1998.

29. Nijhawan RI, Molenda M, Zirwas MJ, et al. Systemic contact dermatitis. Dermatol Clin. 2009;27(3):35564.

30. Patriarca M, Lyon TD, Fell GS. Nickel metabolism in humans investigated with an oral stable isotope. Am J Clin Nutr. 1997;66:616-21.

31. Roy CN, Enns CA. Iron homeostasis: new tales from the crypt. Blood. 2000;96(13):4020-7.

32. Tallkvist J, Bowlus CL, Lonnerdal B. Effect of iron treatment on nickel absorption and gene expression of the divalent metal transporter (DMT1) by human intestinal Caco-2 cells. Pharmacol Toxicol. 2003;92(3):121-4.

33. Moloney FJ, Hughes R, O'Shea D, et al. Type I immediate hypersensitivity reaction to cyanocobalamin but not hydroxycobalamin. Clin Exp Dermatol. 2008;33(4):412-4.
34. Heyworth-Smith D, Hogan PG. Allergy to hydroxycobalamin, with tolerance of cyanocobalamin. Med J Aust. 2002;177(3):162-3.

35. Expert Group on Vitamins and Minerals. Review of cobalt. UK Food Standards Agency, 2002.

36. Sharma AD. Low chromate diet in dermatology. Indian J Dermatol. 2009;54(3):293-5.

37. Cabrera-Vique C, Teissedre PL, Cabanis MT, et al. Determination and levels of chromium in French wine and grapes by graphite furnace atomic absorption spectrometry. J Agric Food Chem. 1997;45:1808-11.

38. Dattilo AM, Miguel SG. Chromium in health and disease. Nutr Today. 2003;38:121-33.

39. Anderson RA, Bryden NA, Polansky MM. Dietary chromium intake: freely chosen diets, institutional diets and individual foods. Biol Trace Elem Res. 1992;32:117-21.

40. Saner G. The metabolic significance of dietary chromium. Nutr Int. 1986;2:213-20.

41.• Scheman A, Rakowski E, Chou V, et al. Balsam of Peru: past and future. Dermatitis. 2013;24(4):153-60.

This resource classifies balsam of Peru, or Myroxylon pereirae, subgroups in foods. Use of allergen subgroups can help broaden a sensitive patient's diet, since many patients do not need to avoid all Myroxylon pereirae subgroups, depending on individual sensitivities

42. Salam TN, Fowler JF. Balsam-related systemic contact dermatitis. J Am Acad Dermatol. 2001;45(3):377-81.

43.• Scheman A, Cha C, Jacob S, et al. Food avoidance diets systemic, lip, and oral contact allergy: an American Contact Alternatives Group article. Dermatitis. 2012;23(6):248-57.

Oral contact allergen elimination diets with detailed charts are available in this reference

44. Warshaw EM, Botto NC, Zug KA, et al. Contact dermatitis associated with food: retrospective crosssectional analysis of North American Contact Dermatitis Group data 2001-2004. Dermatitis. 2008;19(5):252-60.

45. Wintzen M, Donker AS, van Zuuren EJ. Recalcitrant atopic dermatitis due to allergy to Compositae. Contact Dermatitis. 2003;48(2):87-8.

46. Hill AM, Belsito DV. Systemic contact dermatitis of the eyelids caused by formaldehyde derived from aspartame? Contact Dermatitis. 2003;49(5):258-9.

47. Cashman AL, Warshaw EM. Parabens: a review of epidemiology, structure, allergenicity, and hormonal properties. Dermatitis. 2005;16(2):57-66.

48. Soni MG, Taylor SL, Greenberg NA, et al. Evaluation of the health aspects of methyl paraben: a review of the published literature. Food Chem Toxicol. 2002;40(10):1335-73.

49.• Tammaro A, Narcisi A, Persechino S, et al. Topical and systemic therapies for nickel allergy. Dermatitis. 2011;22(5):251-5.

This concise review article addresses treatments for nickel contact dermatitis

50. Kaaber K, Menné T, Veien N. Antabuse treatment of nickel dermatitis. Chelation- a new principle in the 
treatment of nickel dermatitis. Contact Dermatitis. 1979;5(4):221-8.

51. Menné T, Kaaber K, Tjell JC. Treatment of nickel dermatitis. Ann Clin Lab Sci. 1980;10(2):160-4.

52. Robertson L. New and existing therapeutic options for hand eczema. Skin Ther Lett. 2009;14(3):1-5.

53. Mansfield LE, Urrea L, Hutteman HR. Tolerance to cobalt after immunotherapy for cobalt hypersensitivity. Ann Allergy Asthma Immunol. 2012;108(5):382-3.

54.• Di Gioacchino M, Ricciardi L, De Pità O, et al. Nickel oral hyposensitization in patients with systemic nickel allergy syndrome. Ann Med. 2014;46(1):31-7.

This is the first published randomized, double-blind, placebocontrolled trial addressing nickel hyposensitization in patients with systemic nickel allergy syndrome. It demonstrates statistically significant improvement in gastrointestinal symptoms in patients, with a trend toward skin symptom improvement 55. Bonamonte D, Cristaudo A, Nasorri F, et al. Efficacy of oral hyposensitization in allergic contact dermatitis caused by nickel. Contact Dermatitis. 2011;65(5):293-301.
56. Ricciardi L, Carni A, Loschiavo G, et al. Systemic nickel allergy: oral desensitization and possible role of cytokines Interleukin 2 and 10. Int J Immunopathol Pharmacol. 2013;26(1):251-7.

57. Soyer OU, Akdis M, Akdis CA. Mechanism of subcutaneous allergen immunotherapy. Immunol Allergy Clin N Am. 2011;31(2):175-90.

58. Cavani A, Nasorri F, Ottaviani C, et al. Human CD25+ regulatory $\mathrm{T}$ cells maintain immune tolerance to nickel in healthy, nonallergic individuals. J Immunol. 2003;171(11):5760-8.

59. Matiz C, Jacob SE. Systemic contact dermatitis in children: how an avoidance diet can make a difference. Pediatr Dermatol. 2011;28(4):368-74.

These authors report 8 children with systemic contact dermatitis who improve with avoidance diets. Factors specific to pediatric systemic contact allergy are addressed in the article.

60. Herro EM, Jacob SE. Systemic contact dermatitis: kids and ketchup. Pediatr Dermatol. 2013;30(3):e32-3. 